\title{
Civil Satellite Positioning Systems
}

\author{
Andrew S. Bogle
}

(John E. Chance \& Associates, Inc.)

In his recent paper, Blanchard ' gave a good assessment of commercial satellite positioning systems. I would, however, like to update a number of points made in his paper concerning STARFIX and its operations.

The area of coverage shown in the diagram accompanying the article is the three satellite footprint. A fourth satellite (GTE Spacenet I) was incorporated into the system in August 1988. The combined footprint now provides positioning coverage over almost the entire North American continent (Fig. 1). Although most STARFIX operations occur in the Gulf of Mexico, the system continues to be used throughout the coverage area.

The addition of the fourth satellite provides an important level of redundancy to the system, enabling the user to continue positioning from any three of the four satellite constellations during periods of single satellite outages. In addition, STARFIX is now able to track orbit manoeuvres with minimal system error. This is due to changes in the

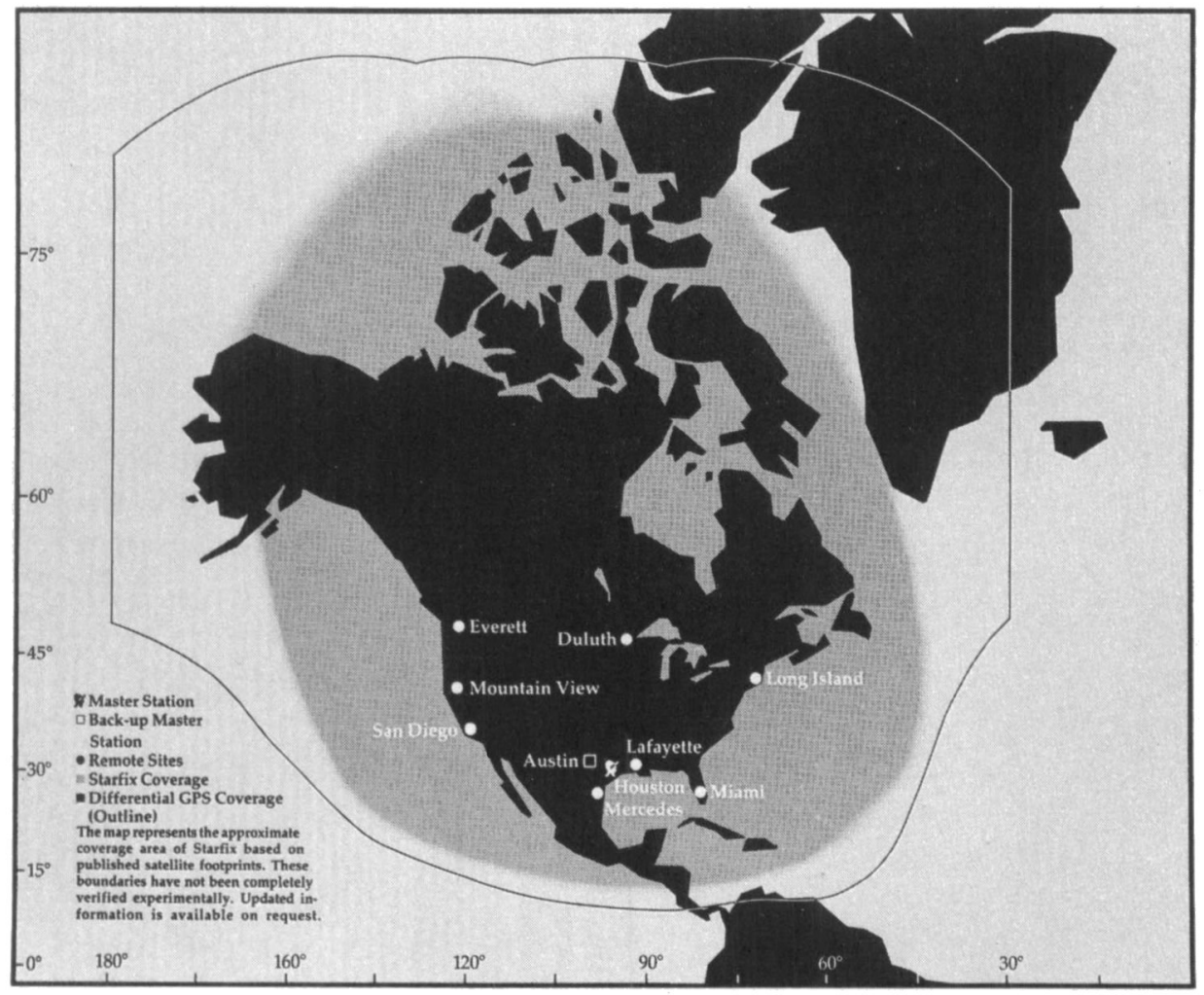

Fig. I. STARFIX coverage diagram 
satellite operators' procedures, where orbit adjustments are now carried out over a two to three hour period instead of the original procedure which utilized a 'bang-bang' principle.

Tests throughout the coverage area continue to be made. Practical limitations are inherent in geosynchronous satellite systems at the polar and equatorial regions as pointed out by Blanchard. Experience shows that the position determination rapidly deteriorates starting at $15^{\circ}$ latitude, worsening towards the equator. Tests on the Alaska North Slope $\left(70^{\circ} \mathrm{N}\right)$, have indicated that the system is usable with satellite elevations of less than $5^{\circ}$, provided that a clear line of sight is available.

Finally, a note on the user equipment. Realizing the limitations of the current mobile system due to both size and performance, a major research and development initiative was launched to improve the receiver capabilities, while at the same time substantially reducing its physical size. A prototype of the newly designed receiver, together with an omni-directional antenna, will be tested mid-1989.

\section{R EF ER E N C E}

1 Blanchard W. F. (1989). Civil satellite navigation and location systems. This Journal, 42, 202 .

$$
\text { KEY WORDS }
$$

I. Satellite systems. 2. Radio navigation. 